\title{
Trematode infection correlates with shell shape and defence morphology in a freshwater snail
}

\author{
E. P. LEVRI*, J. DILLARD and T. MARTIN \\ Division of Math and Sciences, 3000 Ivyside Park, Penn State-Altoona, Altoona, PA 16601, USA
}

(Received 21 October 2004; revised 14 December 2004; accepted 15 December 2004)

\begin{abstract}
SUMMARY
Parasitism often influences the phenotype of individuals. Many of the resulting changes are due to changes in resource allocation that come with infection. Here we examine the effect of a trematode parasite on the shape and defence morphology of a New Zealand freshwater snail, Potamopyrgus antipodarum. The trematode Microphallus sp. asexually produces hundreds of metacercarial cysts in the snail. The length, width and 2-dimensional area of each snail were measured. Snails were also assessed for their degree of spininess. Snails were dissected to determine gender, brooding condition and parasitism. Snails infected with Microphallus sp. were found to be significantly less spiny than uninfected snails. Microphallus-infected snails were also found to have a significantly greater width to length ratio at larger sizes than their uninfected counterparts. These trends could be explained in at least 3 ways. (1) Infection causes the snails to not produce spines and to become wider. (2) Spiny and narrower snails are more likely to die when they become infected. (3) Spiny and narrower snails are more resistant to infection. The changes in phenotype observed are unlikely to be adaptive for either the host or parasite and probably represent physiological by-products of the host-parasite relationship.
\end{abstract}

Key words: Potamopyrgus antipodarum, Microphallus, trematode, shell morphology, spines.

\section{INTRODUCTION}

Infection by parasites has been shown to influence many aspects of host phenotype including physiology (Thompson, 1990), life-history (Minchella, 1985), behaviour (Moore, 2002), sexually selected traits (Zuk, 1992), and morphology (McCarthy, Fitzpatrick \& Irwin, 2004). These effects can change the mean value of a trait, the variance, or both (Poulin \& Thomas, 1999). Relatively little work has been done to examine the effect of parasitism on the morphology of molluscs (but see Krist, 1998; McCarthy et al. 2004). Changes in morphology can include changes in shell size, shell shape or shell ornamentation.

Most studies examining the effect of parasitism on shell morphology in molluscs have studied the growth rate. Outcomes vary from no effect of parasitism on growth rate (Fernandez \& Esch, 1991), to decreased growth rates (Sousa, 1983; Crews \& Yoshing, 1989; Krist \& Lively, 1998) to increased growth rates (Rothschild \& Rothschild, 1939; Mouritsen \& Jensen, 1994; Ballabeni, 1995; Krist, 2000), which is often referred to as gigantism. Gigantism has been interpreted in several ways: (1) as a by-product of the parasitic castration where hosts that no longer invest energy in reproduction divert at least some of this energy into increasing the growth rate, (2) as an adaptation of the host to outlast

* Corresponding author: Fax: +814 949 5435. E-mail: ep11@psu.edu the parasite (Minchella, 1985), and (3) as an adaptive manipulative effort of the parasite to increase space within the host for parasite growth and reproduction (McCarthy et al. 2004). It is also possible that parasitism may affect the shape by altering the rates of growth in one dimension but not another. A change in growth rate in length but not width, or vice versa, would change the shape and potentially the volume of the host individual. Such changes have been interpreted as adaptive when the volume of the host increased with parasitism and was related to an increase in parasite reproduction (McCarthy et al. 2004).

Parasites may also influence shell ornamentation. Many gastropods produce spiny extensions of the shell as defence or stabilizing structures (Vermeij, 1993). The construction of shell material in molluscs is energetically costly (Brusca \& Brusca, 2003). The energetic drain caused by parasitism may leave little energy available for the production of spines.

Here we examine the effect of castrating trematode parasites on two aspects of the morphology of the New Zealand mud snail, Potamopyrgus antipodarum. Potamopyrgus antipodarum is a small Hydrobiid snail commonly found in New Zealand lakes and streams where it grazes on algae and detritus. It is an intermediate host to a suite of castrating trematode parasites. In Lake Alexandrina on the South Island, the most common parasite by far is Microphallus sp., which ranges in infection rate from about $3 \%$ to over $50 \%$ depending upon time and location within the lake (Jokela \& Lively, $1995 a$; Levri unpublished 
data). Microphallus has a 2-host life-cycle. Adult worms reproduce sexually in the guts of waterfowl. Eggs are passed out with the faeces and consumed by Potamopyrgus. The eggs eventually produce hundreds of metacercarial cysts castrating the snail host. The life-cycle is completed when infected snails are eaten by waterfowl.

Microphallus has been demonstrated to influence the behaviour (Levri \& Lively, 1996; Levri, $1998 a, b$; Levri, 1999; Levri \& Fisher, 2000) and life-history (Lively, 1987; Jokela \& Lively, 1995 ; Krist \& Lively, 1998) of this snail species. The snail varies in maximum length by geographical location (Winterbourn, 1970), and even by depth within a lake (Jokela \& Lively, 1995a). Populations vary considerably in spine production, both in frequency of individuals with spines and the size of the spines (Winterbourn, 1970). Both environmental and genetic influences have been implicated in determining the degree of spininess in individuals (Winterbourn, 1970). In the shallow waters of Lake Alexandrina spine production is modest compared to other lakes, as the majority of snails do not produce spines or ridges.

We assessed the effect of Microphallus on the snail's shape (e.g. length to width ratio) and defence morphology (spine production). Potamopyrgus produces spines primarily composed of the periostracum layer of the shell, which is largely protein and thus would be energetically costly to produce (Winterbourn, 1970). The snail also shows substantial variation in shape between locations (Winterbourn, 1970). This variation in shape leads to differences in overall shell volume at a given length. Asexual reproduction by Microphallus within the snail results in hundreds of metacercarial cysts. Theoretically, this reproduction may be limited by shell volume, which has been found in other microphallid-infected gastropods (McCarthy et al. 2004).

\section{MATERIALS AND METHODS}

Snails were collected from shallow-water habitats $(<1 \mathrm{~m})$ in Lake Alexandrina, South Island, New Zealand using dip nets in December of 2002. The snails were preserved in $70 \%$ ethanol and returned to the lab for measurement and dissection. Prior to dissection a digital photograph was taken of each snail using a SPOT Insight Digital camera. For the photograph, each snail was oriented in the same way. All were placed with the shell opening facing up. Each snail was measured using SPOT Insight software. Three measurements were taken for each snail (Fig. 1): length from one end to the other, the width of the most recently grown whorl (whorl 1), and the 2-dimensional area of the entire snail from the digital image.

Each snail was then assessed for the degree of spininess. We subjectively categorized each snail

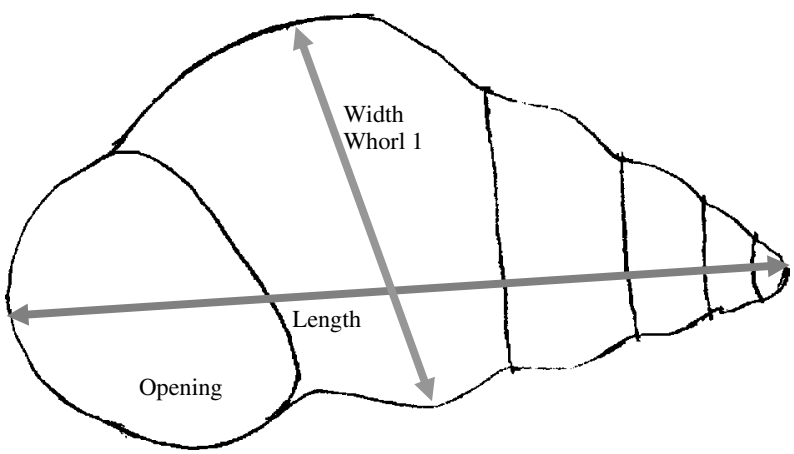

Fig. 1. Drawing of a snail showing the various measurements taken to examine shape. The area of the snail was measured by tracing the outline of the entire 2-dimensional image.

prior to dissection using a scale from 0 to 3 (Fig. 2). A score of 0 indicated no spines or ridges. A score of 1 was given to snails with a ridge, a 2 was given to snails with short spines, and a 3 was given to snails with long spines. The spininess score was given based on assessment of the most recently grown whorl of the snail (whorl 1 in Fig. 1). This was done because, in some snails, the spininess changed as the snail grew.

Each snail was then dissected and gender, brooding condition, infection and type of parasite was noted for each snail. Parasites were identified in part using the descriptions provided by Winterbourn (1974). The snails were separated into 5 mutually exclusive classes including uninfected non-brooding females, uninfected brooding females, uninfected males, Microphallus-infected snails, and snails infected with parasites other than Microphallus. Snails infected with Microphallus and other parasites were rare and were eliminated from the study.

The effect of parasitism on shell shape was analysed using ANCOVA with the length of the snail used as a covariate, width of the first whorl and the square root of the area of the snail used as dependent variables, snail class as an independent variable, and a Type I sum of squares. The various classes of snails were compared in a pair-wise manner. A Levene's test for homogeneity of variance test was performed for each comparison to test for violations of this assumption of ANCOVA. Each pair of classes was first compared by testing for significant differences in the slopes of the regression lines produced by each class. This was done by examination of the interaction between snail class and length. A significantly different slope indicates a significant difference in shapes between the two classes. If there was no significant difference in slopes between the two classes (or the test yielded marginally significant results $[0 \cdot 01<P<0 \cdot 10])$, a second test was performed without using the snail class by length interaction term in the model. Here a significant effect of class would indicate a significant vertical shift in the regression 


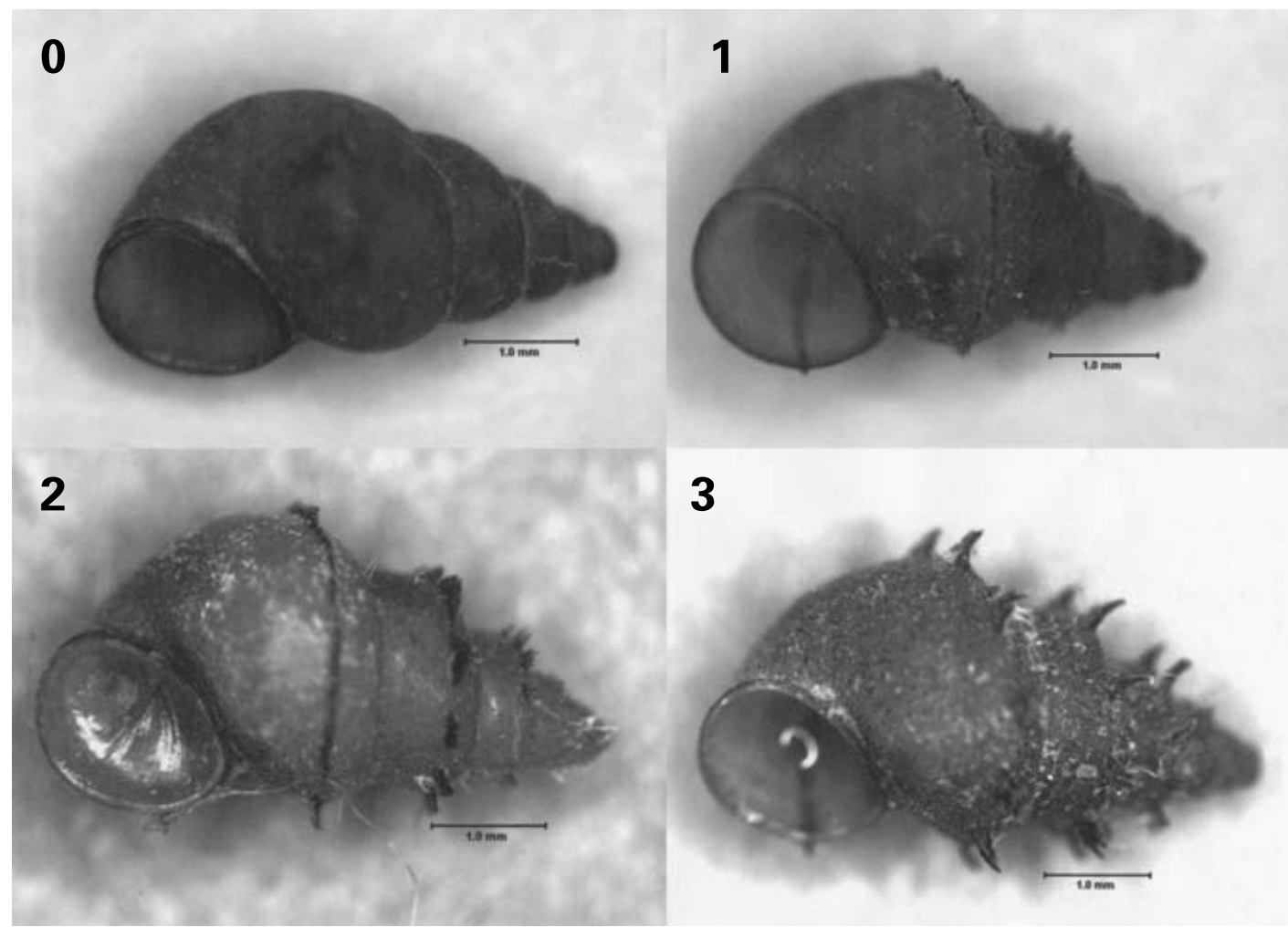

Fig. 2. Photographs of typical snails representing each of the four spininess categories.

lines between the two classes and would also indicate a significant difference in shape between the two groups.

The effect of parasitism on spininess was examined by using log-linear analyses comparing the proportion of spiny individuals in each snail class using pair-wise comparisons. In each class of snails, snails between 3 and $3.9 \mathrm{~mm}$ in length were compared to snails greater than $3.9 \mathrm{~mm}$ in length to determine if size and/or age influenced defence structures. Since this population of snails has relatively few snails with long spines (score of 3 ), snails with scores of 2 and 3 were grouped together.

\section{RESULTS}

\section{The effect of parasitism on shape}

A total of 375 snails were measured and dissected for this part of the study, of which 96 were infected by Microphallus, and 15 were infected by other castrating trematodes. These other infections included Telogaster opistorchis, Furcouscercaria, Gymnocephalous, and one or two undescribed species of monostomes (listed in Winterbourn, 1974). An ANCOVA with length as a covariate and the width of the first (most recently grown) whorl as an independent variable was used to compare various groups of snails. Since it is known that the probability of infection increases with age (length) (Jokela
\& Lively, 1995a), we were concerned that if the relationship between length and width (or square root of the area) was not precisely linear, then differences between groups may be an artifact of differences in length distribution. Thus, the statistical analyses were run under two different conditions. First, only snails greater than $3.0 \mathrm{~mm}$ for males and snails greater than $3.7 \mathrm{~mm}$ for females (females are on average larger than males) were used in this analysis. Then all snails of all lengths were used in the analysis. Since the results did not differ between the two analyses in every case but one, we present most of the data using all lengths of snails. The only exception is in comparing uninfected non-brooding female snails to uninfected brooding female snails. In this case, the analysis using snails of all sizes did not meet the assumption of equality of variances, but using sizes greater than $3.0 \mathrm{~mm}$ and less than $4.5 \mathrm{~mm}$ did meet the assumption. Detailed results from the statistical analysis of shape can be found in the Appendix.

Uninfected brooding females were found to be significantly longer than uninfected non-brooding females $(P<0 \cdot 001)$, uninfected females were found to be significantly longer than uninfected males $(P<0 \cdot 001)$, and infected snails were found to be significantly longer than uninfected snails $(P<$ $0 \cdot 001)$. No difference in shape was found between brooding and non-brooding females (see Tables 1 and 2) thus brooding and non-brooding females were grouped together in subsequent analyses. Uninfected 
Table 1. Results of ANCOVA using length as a covariate and width of whorl 1 as an independent variable

\begin{tabular}{|c|c|c|c|c|c|}
\hline \multirow[b]{2}{*}{ Classes compared } & \multirow[b]{2}{*}{$\mathrm{R}^{2}$} & \multicolumn{2}{|l|}{ Slope } & \multicolumn{2}{|c|}{ Vertical shift } \\
\hline & & $\mathrm{F}$ & $P$ & $\mathrm{~F}$ & $P$ \\
\hline $\begin{array}{l}\text { Uninfected non-brooding females } v s \\
\text { Uninfected brooding females }\end{array}$ & $\begin{array}{l}0 \cdot 58 \\
0 \cdot 54\end{array}$ & $0 \cdot 010$ & $=0 \cdot 92$ & $2 \cdot 353$ & $=0 \cdot 13$ \\
\hline $\begin{array}{l}\text { Uninfected females vs } \\
\text { Uninfected males }\end{array}$ & $\begin{array}{l}0 \cdot 79 \\
0 \cdot 67\end{array}$ & $1 \cdot 779$ & $=0 \cdot 18$ & $33 \cdot 536$ & $<0.001$ \\
\hline $\begin{array}{l}\text { Uninfected females } v s \\
\text { Microphallus-infected females }\end{array}$ & $\begin{array}{l}0 \cdot 79 \\
0 \cdot 76\end{array}$ & $6 \cdot 775$ & $=0 \cdot 01$ & $344 \cdot 8$ & $<0 \cdot 001$ \\
\hline $\begin{array}{l}\text { Uninfected males vs } \\
\text { Microphallus-infected males }\end{array}$ & $\begin{array}{l}0 \cdot 67 \\
0 \cdot 82\end{array}$ & $0 \cdot 577$ & $=0 \cdot 45$ & $0 \cdot 461$ & $=0.503$ \\
\hline $\begin{array}{l}\text { Uninfected females } v s \\
\text { Female snails infected with other parasites }\end{array}$ & $\begin{array}{l}0 \cdot 79 \\
0 \cdot 89\end{array}$ & $4 \cdot 179$ & $=0 \cdot 42$ & $0 \cdot 082$ & $=0 \cdot 775$ \\
\hline $\begin{array}{l}\text { Microphallus-infected females vs } \\
\text { Female snails infected with other parasites }\end{array}$ & $\begin{array}{l}0 \cdot 76 \\
0 \cdot 89\end{array}$ & $0 \cdot 714$ & $=0 \cdot 40$ & $0 \cdot 994$ & $=0 \cdot 321$ \\
\hline
\end{tabular}

Table 2. Results of ANCOVA using length as a covariate and the square root of the 2-dimensional area as independent variable

(Vertical shift was not tested for uninfected females compared to Microphallus-infected snails because of the strongly significant differences in slopes.)

\begin{tabular}{|c|c|c|c|c|c|}
\hline \multirow[b]{2}{*}{ Classes compared } & \multirow[b]{2}{*}{$\mathrm{R}^{2}$} & \multicolumn{2}{|l|}{ Slope } & \multicolumn{2}{|c|}{ Vertical shift } \\
\hline & & $\mathrm{F}$ & $P$ & $\mathrm{~F}$ & $P$ \\
\hline $\begin{array}{l}\text { Uninfected non-brooding females } v s \\
\text { Uninfected brooding females }\end{array}$ & $\begin{array}{l}0 \cdot 80 \\
0 \cdot 79\end{array}$ & 0.575 & $=0 \cdot 45$ & $0 \cdot 220$ & $=0 \cdot 64$ \\
\hline $\begin{array}{l}\text { Uninfected females } v s \\
\text { Uninfected males }\end{array}$ & $\begin{array}{l}0 \cdot 93 \\
0 \cdot 92\end{array}$ & $1 \cdot 625$ & $=0 \cdot 20$ & $14 \cdot 550$ & $<0 \cdot 001$ \\
\hline $\begin{array}{l}\text { Uninfected females } v s \\
\text { Microphallus-infected females }\end{array}$ & $\begin{array}{l}0 \cdot 93 \\
0.92\end{array}$ & $15 \cdot 51$ & $<0 \cdot 001$ & & \\
\hline $\begin{array}{l}\text { Uninfected males } v s \\
\text { Microphallus-infected males }\end{array}$ & $\begin{array}{l}0.93 \\
0.96\end{array}$ & $0 \cdot 052$ & $=0 \cdot 82$ & $1 \cdot 216$ & $=0 \cdot 28$ \\
\hline $\begin{array}{l}\text { Uninfected females } v s \\
\text { Female snails infected with other parasites }\end{array}$ & $\begin{array}{l}0 \cdot 92 \\
0 \cdot 92\end{array}$ & $1 \cdot 904$ & $=0 \cdot 17$ & $0 \cdot 389$ & $=0.53$ \\
\hline $\begin{array}{l}\text { Microphallus-infected females vs } \\
\text { Female snails infected with other parasites }\end{array}$ & $\begin{array}{l}0 \cdot 92 \\
0 \cdot 92\end{array}$ & $0 \cdot 056$ & $=0 \cdot 81$ & 1.987 & $=0 \cdot 162$ \\
\hline
\end{tabular}

female snails were found to have a significantly greater width per unit length than uninfected males (Table 1). Because of this, infected and uninfected males and females were not grouped in subsequent analyses. Microphallus-infected female snails were found to have significantly different slopes from uninfected female snails (Tables 1 and 2). On average, infected snails had a greater width to length ratio as length increased (Fig. 3A). Microphallus-infected males were not significantly different from uninfected males (Tables 1 and 2). However, there was a very low sample size of infected males (7). Low sample sizes of snails infected by other castrating trematodes limited our ability to detect differences between them and other classes. However, the regression line of snails infected with other parasites was very similar to Microphallus-infected snails (Fig. 3B). An analysis with length as the covariate and the square-root of the 2-dimensional area yielded similar results to the analysis utilizing the width of the first whorl (Table 2).

\section{The effect of parasitism on defence morphology}

A total of 2574 snails were scored and dissected for this part of the study, of which 1129 were infected by Microphallus, and 154 were infected by other castrating trematodes.

No effect of length was found when comparing large to small individuals in any snail class $(P>0.33$ in all cases). Thus, large and small individuals were grouped together for subsequent analyses. The uninfected classes (non-brooding females, brooding females, and males) showed no differences in their proportion of spiny individuals (at least $P>0 \cdot 24$ in all cases). Significant differences were found between all infected snails and all uninfected snails (Table 3; Fig. 4), as well as between Microphallus-infected snails and all uninfected snail classes $(P<0 \cdot 01$ in all cases). In general, there were fewer spiny individuals found in the infected classes. No difference was found between Microphallus-infected snails and snails infected with other castrating trematodes, but 

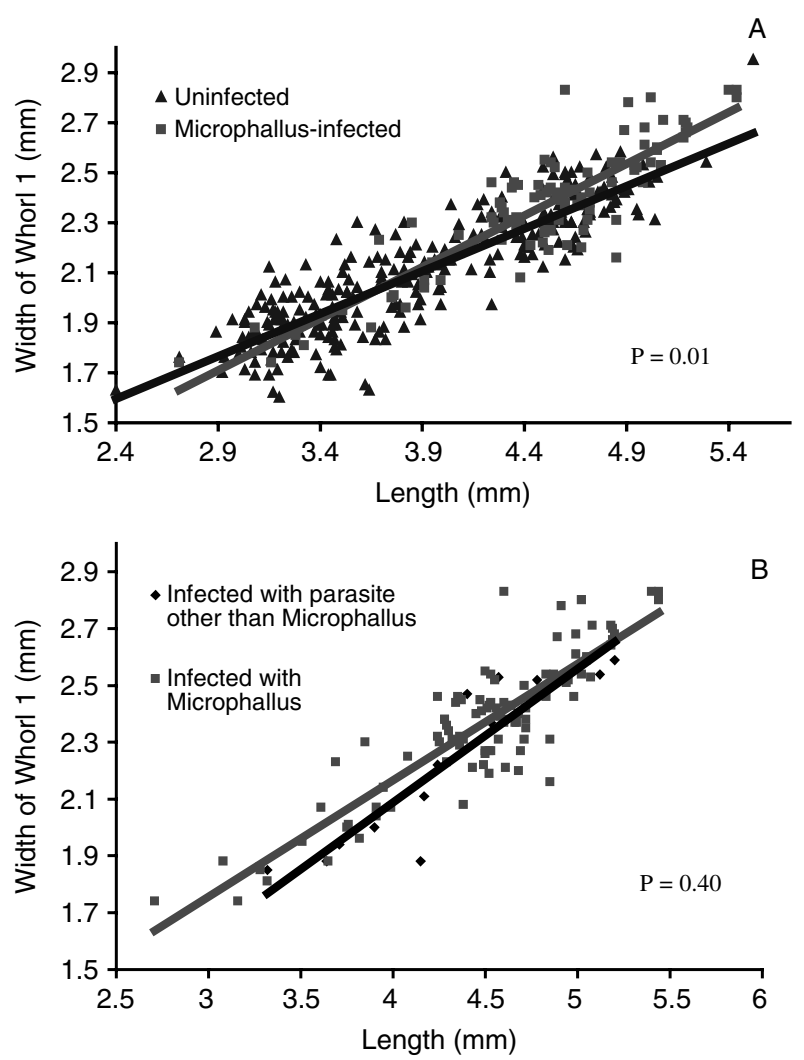

Fig. 3. The relationship between length and width of whorl 1 in Microphallus-infected and uninfected snails (A) and Microphallus-infected snails and snails that are infected with parasites other than Microphallus (B). Microphallus-infected snails show a significantly different shape than uninfected snails. $P$-values on the graphs represent the tests performed to determine differences in slopes.

no difference was also found between snails infected with trematodes other than Microphallus and uninfected snails. The sample size of snails infected with parasites other than Microphallus was limited here, however.

\section{DISCUSSION}

Snail classes could have different shapes in two possible ways. First, the slopes of the regression lines of the classes could be significantly different. This was the case for snails infected with Microphallus compared to uninfected females. Here the slope of the line for Microphallus-infected snails was significantly greater than the slope of uninfected females, indicating greater width to length and square root area to length ratios. This result is probably best explained by the fact that infected snails were once uninfected. The probability of infection increases with age and older (longer) snails are more likely to have been infected for a longer time than younger (shorter) snails. Thus the smaller infected snails used in the analysis were likely only recently infected. At small sizes there was little difference between infected and uninfected snails due to the lack of time for the parasite to have any pronounced effect on growth. However, for larger snails, a significant proportion of snails were infected for a longer period of time, and the difference between infected and uninfected snails is more pronounced. The regression lines of Microphallus-infected snails and uninfected females intersect at about $3.7 \mathrm{~mm}$ in length. Detectable Microphallus-infection does not usually become common in snails until a length of about $4.0 \mathrm{~mm}$.

If the slopes of the regression lines were not significantly different, an ANCOVA was performed to test for a vertical shift in the regression lines. Such a shift would indicate a significantly greater width to length ratio (or square root area to length ratio) at all lengths. Such a difference was found between uninfected males and uninfected females. Since some of the differences in slopes were marginally significant, the ANCOVA was performed as a precaution in case the slope differences were simply due to chance.

Here we show that Potamopyrgus antipodarum infected with Microphallus are shaped differently from and are less likely to produce spines than uninfected snails. These results could be explained in at least three ways. (1) The infection influences the growth pattern and spine production in the snails. (2) Wider and smoother snails are more likely to become infected. The probability of this is reasonable in this system because the snails in Lake Alexandrina (as well as other lakes) live in a mixed population of sexual and asexual individuals, and the frequency of clones varies over time. Some clones tend to be spinier than others, and some clones have shown greater abilities than others to resist infection (Lively \& Dybdahl, 2000; Lively, personal communication). (3) Parasitism results in differential mortality due to higher parasite-induced death rates in narrower and spinier snails. Spiny snails are allocating more energy to spine production than smooth snails. When infected, the parasite usurps a certain amount of resources from the snail, and if the snails make spines as well, there may not be enough resources remaining to sustain the snail, thus increasing mortality. With regard to shape, if a certain number of metacercariae are always produced, that number in a wider snail may be able to be sustained, while in a narrow snail that number of metacercariae may stress the snail to a greater degree, increasing mortality. This seems unlikely from an evolutionary standpoint however. It would make more sense for the parasite to adjust the number of metacercariae based on the size of the snail. To produce too many may result in the death of the parasite as well. Although, if a certain number of metacercariae are required to reach a critical threshold population size in the waterfowl gut, selection may act to maintain a high number of metacercariae despite the mortality cost to the snail and parasite. 
Table 3. Results of pair-wise log-linear analyses comparing proportion of spiny individuals between snail classes

\begin{tabular}{llll}
\hline \hline Classes compared & D.F. & Chi square & $P$ \\
\hline All uninfected vs All infected & 2 & 31.06 & $<0.0001$ \\
All uninfected vs Microphallus-infected & 2 & 32.98 & $<0 \cdot 0001$ \\
All uninfected vs Other parasite infected & 2 & 1.52 & $=0.4676$ \\
Microphallus-inf. vs Other parasite inf. & 2 & 2.40 & $=0.3018$ \\
\hline \hline
\end{tabular}

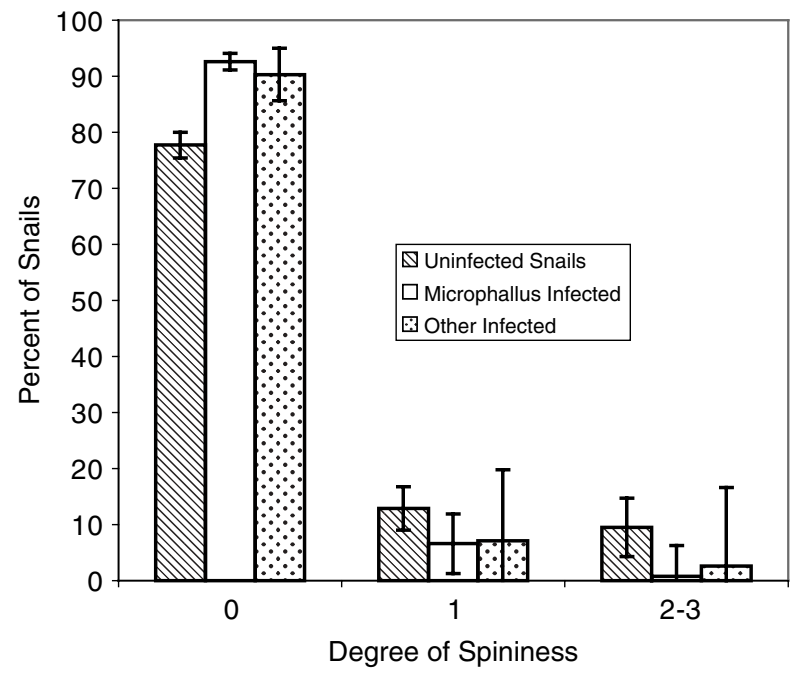

Fig. 4. The proportion of uninfected, Microphallusinfected, and snails infected with other parasites within each spininess class. Microphallus-infected snails are significantly less spiny than uninfected snails.

Since this study was performed on snails captured and preserved in the field, we cannot differentiate between these alternatives here. Anecdotally, however, with regard to spine production, we noticed that infected snails often had a smooth first (most recently produced) whorl, but would have spiny second or third whorls. This suggests that spininess changed since the time of infection in these individuals. Unfortunately, this was not quantified during this study. We plan future studies to quantify the change in spininess within snails as they age and future experiments utilizing experimental infections to distinguish among the above three hypotheses.

If infection does cause changes in shape and defence morphology in individuals, then these changes could result in reduced fitness consequences for the snails. Spines in this system are hypothesized to reduce the probability of being eaten by predatory fish. The most common fish in Lake Alexandrina, the common bully (Gobiomorphus cotidianus), has been shown to eat Potamopyrgus in relatively large numbers (Levri, 1998a). Gobiomorphus is gape limited and has been shown to consume only snails that are as long or smaller than the width of its mouth (Levri, 1998a). Thus an increase in width of the snail caused by spines or ridges may decrease the probability of predation by this fish. Infection resulting in reduced spininess may increase the mortality rate of the snails due to predation and also increase the mortality rate of the parasite in the process. Changes in shell shape can influence fitness by changing the ability of the shell to withstand the force of crushing predators and thus increase the likelihood of surviving an attack (Appleton \& Palmer, 1988; Krist, 1998, 2002).

In this study, uninfected females were found to be significantly longer than uninfected males, uninfected brooding females were found to be significantly longer than uninfected non-brooding females, and infected snails were found to be significantly longer than uninfected snails. All of these results are consistent with the results of previous studies utilizing this system (Jokela \& Lively, $1995 b$; Levri \& Lively, 1996). Since females brood their offspring in a brood chamber, there is likely to be a reproductive advantage for larger females. Larger females have on average larger broods (Levri, unpublished data). As females get larger, a greater proportion of them can be found brooding, thus increasing the mean length of brooding females compared to nonbrooding females (Levri, unpublished data). The reason for a greater length of infected snails is less straightforward. Infected snails grow at a slower rate than uninfected snails, at least when infected as juveniles (Krist \& Lively, 1998). The most likely explanation is simply that the probability of having encountered a parasite increases with age. Thus older (longer) snails have a greater probability of being infected (Jokela \& Lively, 1995a).

It cannot be determined for either shape or spininess whether the effects are Microphallus-specific or not. In both cases, snails infected with parasites other than Microphallus were not significantly different from Microphallus-infected snails and uninfected snails. The lack of differences here are likely due to the limited sample sizes of snails infected with other parasites. However, visually, snails infected with other parasites appear more similar to Microphallus-infected snails than to uninfected snails. This suggests, inconclusively, that parasitism, in general, results in changes in shape and defence morphology. If true, this would make explanations for the changes due to adaptations on the part of Microphallus less likely.

McCarthy et al. (2004) found that Littorina saxatilis infected by Microphallus piriformes were shaped 
differently than uninfected snails. They concluded that the effect of the parasite was adaptive in that it increased the volume of infected snails resulting in increased space for the asexual production of metacercariae. Results here are a bit different. McCarthy et al. (2004) found that parasitism resulted in snails with a greater length to width ratio, while here we found that infected snails have a lower length to width ratio. Also, Krist \& Lively (1998) found that juvenile Potamopyrgus antipodarum infected with Microphallus grew at a significantly slower rate than uninfected snails. Coupled with these results, it appears that the parasite may decrease the rate of growth in length to a greater degree than it influences the growth in width. This appears to make the adaptive manipulation of shape by the parasite in this system less likely. However, it is possible that given reduced growth rate caused by parasitism, the parasite may be making the best of a bad situation by increasing the growth in width and thus volume.

In conclusion, parasitism in Potamopyrgus is related to shell shape and defence morphology. Infected snails show a lower probability of being spiny and tend to be wider for a given length as length increases. The mechanism that results in this relationship cannot be determined from this study.

We would like to thank Carolyn Itle for help with snail collection in the field, Becky Carson, Tessa Strittmatter, Shane Lunnen, Erica Meyers, Leocadia Mosquea, Brian Kinkade, Robert Platt, and Justin Winters for assistance in the lab, and Jukka Jokela and Jeffrey Plochocki for statistical advice. We are indebted to Jan MacKenzie and the Edward Percival Field Station and Jack van Berkel for logistical support in New Zealand. The manuscript was improved by comments from Maureen Levri. This project was supported by grants from Penn State - Altoona and the Darbaker Research Grant from the Pennsylvania Academy of Science.

\section{REFERENCES}

APPLETON, R. D. \& PALMER, A. R. (1988). Water-borne stimuli released by predatory crabs and damaged prey induce more predator-resistant shells in a marine gastropod.

Proceedings of the National Academy of Sciences, USA 85, 4387-4391.

BALlABENI, P. (1995). Parasite-induced gigantism in a snail: a host adaptation? Functional Ecology 9, 887-893.

BRUSCA, R. C. \& BRUSCA, G. J. (2003). Invertebrates, 2nd Edn. Sinauer Associates, Inc., Sunderland, Massachusetts. CREWS, A. E. \& Yoshing, T. P. (1989). Schistosoma mansoni-effect of infection on reproduction and gonadal growth in Biomphalaria glabrata. Experimental Parasitology 68, 302-334.

FERNANDEZ, J. \& ESCH, G. W. (1991). Effect of parasitism on the growth rate of the pulmonate snail Helisoma anceps. Fournal of Parasitology 77, 937-944.

JOKELA, J. \& LIVELY, C. M. (1995a). Spatial variation for infection by digenetic trematodes in a population of freshwater snails (Potamopyrgus antipodarum). Oecologia 103, 509-517.
JOKela, J. \& Lively, C. M. (1995 b). Parasites, sex, and early reproduction in a mixed population of freshwater snails. Evolution 49, 1268-1271.

KRIST, A. C. (1998). The effects of parasites and predators on the life-history and morphology of freshwater snails. $\mathrm{Ph} . \mathrm{D}$. Dissertation. Indiana University, Bloomington, IN, USA.

KRIST, A. C. (2000). Effect of the digenean parasite Proterometra macrostoma on host morphology in the freshwater snail Elimia livescens. Fournal of Parasitology 86, 262-267.

KRIST, A. C. (2002). Crayfish induce a defensive shell shape in a freshwater snail. Invertebrate Biology 121, $235-242$.

KRIST, A. C. \& LIVELY, C. M. (1998). Experimental exposure of juvenile snails (Potamopyrgus antipodarum) to infection by trematode larvae (Microphallus sp.): infectivity, fecundity compensation and growth. Oecologia 116, 575-582.

LEVRI, E. P. (1998a). The influence of non-host predators on parasite-induced behavioural changes in a freshwater snail. Oikos 81, 531-537.

LEVRI, E. P. (1998b). Perceived predation risk, parasitism and the foraging behaviour of a freshwater snail. Canadian Fournal of Zoology 76, 1878-1884.

LEVRI, E. P. (1999). Parasite-induced changes in host behaviour of a freshwater snail: manipulation or byproduct of parasitism. Behavioural Ecology 10, 234-241.

LEVRI, E. P. \& FISHER, L. (2000). The effect of a trematode (Microphallus sp.) on the response of the freshwater snail, Potamopyrgus antipodarum to light and gravity. Behaviour 137, 1141-1151.

LEVRI, E. P. \& LIVELY, C. M. (1996). The effects of size, reproductive condition, and parasitism on the foraging behaviour in a freshwater snail, Potamopyrgus antipodarum. Animal Behaviour 51, 891-901.

Lively, C. M. (1987). Evidence from a New Zealand snail for the maintenance of sex by parasitism. Nature, London 328, 519-521.

LIVELY, C. M. \& DYBDAHL, M. F. (2000). Parasite adaptation to locally common host genotypes. Nature, London 405, 679-681.

MCCARTHY, H. O., FITZPATRICK, S. M. \& IRWIN, S. W. B. (2004). Parasite alteration of host shape : a quantitative approach to gigantism helps elucidate evolutionary advantages. Parasitology 128, 7-14.

MINCHELLA, K. J. (1985). Host life-history variation in response to parasitism. Parasitology 90, 205-216.

moore, J. (2002). Parasitism and the Behaviour of Animals. Oxford University Press, Oxford.

MOURITSEN, K. N. \& JENSEN, K. T. (1994). The enigma of gigantism: effect of larval trematodes on growth, fecundity, egestion and locomotion in Hydrobia ulvae (Pennant) (Gastropoda: Prosobranchia). Fournal of Experimental Marine Biology and Ecology 181, 53-66.

POUlin, R. \& THOMAS, F. (1999). Phenotypic variability induced by parasites: extent and evolutionary implications. Parasitology Today 15, 28-32.

Rothschild, A. \& ROTHSCHILD, M. (1939). Some observations on the growth of Peringia ulvae (Pennant) (1777) in the laboratory. Novitates Zoologicae 41, 240-247. 
SOUSA, W. P. (1983). Host life-history and the effect of parasitic castration on growth: a field study of Cerithidea californica Haldeman (Gastropoda: Prosobranchia) and its trematode parasites. Fournal of Experimental Marine Biology and Ecology 73, 273-296.

Thompson, s. N. (1990). Physiological alterations during parasitism and their effects on host behaviour. In Parasitism and Host Behaviour (ed. Barnard, C. J. \& Behnke, J. M.), pp. 193-233. Taylor and Francis, London. vermeij, G. J. (1993). A Natural History of Shells. Princeton University Press, Princeton, New Jersey.

winterbourn, M. (1970). The New Zealand species of Potamopyrgus (Gastropoda: Hydrobidae). Malacologia 10, 283-321.

Winterbourn, M. (1974). Larval Trematoda parasitizing the New Zealand species of Potamopyrgus (Gastropoda: Hydrobiidae). Mauri Ora 2, 17-30.

ZUK, M. (1992). The role of parasites in sexual selection: current evidence and future directions. Advances in the Study of Behaviour 21, 39-68.

\section{APPENDIX}

Statistical results from pairwise ANCOVA comparing classes of snails with regard to their width of the first whorl and square root of the two-dimensional area using length as a covariate. Results are shown only for tests where there was no significant difference in the slopes between the two classes or if the difference was marginally significant.

Uninfected non-brooding females $v s$ Uninfected brooding females

Tests of Between-Subjects Effects

\begin{tabular}{|c|c|c|c|c|c|c|}
\hline Source & $\begin{array}{l}\text { Dependent } \\
\text { Variable }\end{array}$ & $\begin{array}{l}\text { Type I Sum } \\
\text { of Squares }\end{array}$ & $\mathrm{df}$ & $\begin{array}{l}\text { Mean } \\
\text { Square }\end{array}$ & $\mathrm{F}$ & $P$ \\
\hline \multirow[t]{2}{*}{ Corrected Model } & width & $3 \cdot 334$ & 2 & $1 \cdot 667$ & $129 \cdot 2$ & $<0.001$ \\
\hline & sqrtarea & $6 \cdot 551$ & 2 & $3 \cdot 276$ & $410 \cdot 3$ & $<0.001$ \\
\hline \multirow[t]{2}{*}{ Intercept } & width & $662 \cdot 4$ & 1 & $662 \cdot 4$ & $51339 \cdot 0$ & $<0.001$ \\
\hline & sqrtarea & $793 \cdot 3$ & 1 & $793 \cdot 3$ & $99376 \cdot 4$ & $<0.001$ \\
\hline \multirow[t]{2}{*}{ Length } & width & $3 \cdot 304$ & 1 & $3 \cdot 304$ & $256 \cdot 0$ & $<0 \cdot 001$ \\
\hline & sqrtarea & $6 \cdot 549$ & 1 & $6 \cdot 549$ & $820 \cdot 4$ & $<0 \cdot 001$ \\
\hline \multirow[t]{2}{*}{ Class } & width & $0 \cdot 0303$ & 1 & $0 \cdot 0303$ & $2 \cdot 353$ & $0 \cdot 127$ \\
\hline & sqrtarea & $0 \cdot 0018$ & 1 & $0 \cdot 0018$ & $0 \cdot 220$ & $0 \cdot 640$ \\
\hline \multirow[t]{2}{*}{ Error } & width & $2 \cdot 026$ & 157 & $0 \cdot 0129$ & & \\
\hline & sqrtarea & $1 \cdot 253$ & 157 & $0 \cdot 0080$ & & \\
\hline \multirow[t]{2}{*}{ Total } & width & $667 \cdot 8$ & 160 & & & \\
\hline & sqrtarea & $801 \cdot 2$ & 160 & & & \\
\hline \multirow[t]{2}{*}{ Corrected Total } & width & $5 \cdot 360$ & 159 & & & \\
\hline & sqrtarea & $7 \cdot 805$ & 159 & & & \\
\hline
\end{tabular}

Uninfected females vs Uninfected males

Tests of Between-Subjects Effects

\begin{tabular}{|c|c|c|c|c|c|c|}
\hline Source & $\begin{array}{l}\text { Dependent } \\
\text { Variable }\end{array}$ & $\begin{array}{l}\text { Type I Sum } \\
\text { of Squares }\end{array}$ & $\mathrm{df}$ & $\begin{array}{l}\text { Mean } \\
\text { Square }\end{array}$ & $\mathrm{F}$ & $P$ \\
\hline \multirow[t]{2}{*}{ Corrected Model } & width & $11 \cdot 76$ & 2 & $5 \cdot 878$ & $486 \cdot 0$ & $<0.001$ \\
\hline & sqrtarea & $21 \cdot 33$ & 2 & $10 \cdot 663$ & $1559 \cdot 8$ & $<0.001$ \\
\hline \multirow{2}{*}{ Intercept } & width & $1119 \cdot 0$ & 1 & $1119 \cdot 0$ & $92518 \cdot 3$ & $<0.001$ \\
\hline & sqrtarea & $1379 \cdot 9$ & 1 & $1379 \cdot 9$ & $201839 \cdot 5$ & $<0.001$ \\
\hline \multirow[t]{2}{*}{ Length } & width & $11 \cdot 35$ & 1 & $11 \cdot 35$ & $938 \cdot 5$ & $<0.001$ \\
\hline & sqrtarea & $21 \cdot 23$ & 1 & $21 \cdot 23$ & $3105 \cdot 0$ & $<0.001$ \\
\hline \multirow[t]{2}{*}{ Class } & width & $0 \cdot 406$ & 1 & $0 \cdot 406$ & $33 \cdot 54$ & $<0 \cdot 001$ \\
\hline & sqrtarea & $0 \cdot 099$ & 1 & $0 \cdot 099$ & $14 \cdot 55$ & $<0 \cdot 001$ \\
\hline \multirow[t]{2}{*}{ Error } & width & $3 \cdot 036$ & 251 & $0 \cdot 0121$ & & \\
\hline & sqrtarea & $1 \cdot 716$ & 251 & $0 \cdot 0068$ & & \\
\hline \multirow{2}{*}{ Total } & width & $1133 \cdot 8$ & 254 & & & \\
\hline & sqrtarea & $1402 \cdot 9$ & 254 & & & \\
\hline \multirow[t]{2}{*}{ Corrected Total } & width & $14 \cdot 79$ & 253 & & & \\
\hline & sqrtarea & $23 \cdot 04$ & 253 & & & \\
\hline
\end{tabular}


Uninfected females vs Microphallus-infected females

Tests of Between-Subjects Effects

\begin{tabular}{|c|c|c|c|c|c|c|}
\hline Source & $\begin{array}{l}\text { Dependent } \\
\text { Variable }\end{array}$ & $\begin{array}{l}\text { Type I Sum } \\
\text { of Squares }\end{array}$ & $\mathrm{df}$ & $\begin{array}{l}\text { Mean } \\
\text { Square }\end{array}$ & $\mathrm{F}$ & $P$ \\
\hline \multirow{2}{*}{ Corrected Model } & width & $18 \cdot 27$ & 2 & $9 \cdot 132$ & $712 \cdot 0$ & $<0 \cdot 001$ \\
\hline & sqrtarea & $34 \cdot 31$ & 2 & $17 \cdot 16$ & $2287 \cdot 2$ & $<0 \cdot 001$ \\
\hline \multirow[t]{2}{*}{ Intercept } & width & $1522 \cdot 8$ & 1 & $1522 \cdot 8$ & $118725 \cdot 3$ & $<0.001$ \\
\hline & sqrtarea & $1893 \cdot 3$ & 1 & $1893 \cdot 3$ & $252410 \cdot 2$ & $<0 \cdot 001$ \\
\hline \multirow[t]{2}{*}{ Length } & width & $13 \cdot 84$ & 1 & $13 \cdot 84$ & $1079 \cdot 2$ & $<0 \cdot 001$ \\
\hline & sqrtarea & $26 \cdot 48$ & 1 & $26 \cdot 48$ & $3530 \cdot 7$ & $<0 \cdot 001$ \\
\hline \multirow[t]{2}{*}{ Class } & width & $4 \cdot 423$ & 1 & $4 \cdot 423$ & $344 \cdot 8$ & $<0 \cdot 001$ \\
\hline & sqrtarea & $7 \cdot 829$ & 1 & $7 \cdot 829$ & $1043 \cdot 8$ & $<0 \cdot 001$ \\
\hline \multirow[t]{2}{*}{ Error } & width & $4 \cdot 015$ & 313 & $0 \cdot 0128$ & & \\
\hline & sqrtarea & $2 \cdot 348$ & 313 & $0 \cdot 0075$ & & \\
\hline \multirow[t]{2}{*}{ Total } & width & $1545 \cdot 1$ & 316 & & & \\
\hline & sqrtarea & $1929 \cdot 9$ & 316 & & & \\
\hline \multirow{2}{*}{ Corrected Total } & width & $22 \cdot 28$ & 315 & & & \\
\hline & sqrtarea & $36 \cdot 66$ & 315 & & & \\
\hline
\end{tabular}

Uninfected males vs Microphallus-infected males

Tests of Between-Subjects Effects

\begin{tabular}{llcccrc}
\hline \hline Source & $\begin{array}{l}\text { Dependent } \\
\text { Variable }\end{array}$ & $\begin{array}{l}\text { Type I Sum } \\
\text { of Squares }\end{array}$ & df & $\begin{array}{l}\text { Mean } \\
\text { Square }\end{array}$ & F & $P$ \\
\hline Corrected Model & width & $1 \cdot 228$ & 2 & $0 \cdot 614$ & $53 \cdot 39$ & $<0 \cdot 001$ \\
& sqrtarea & $1 \cdot 765$ & 2 & $0 \cdot 883$ & $320 \cdot 3$ & $<0 \cdot 001$ \\
Intercept & width & $131 \cdot 5$ & 1 & $131 \cdot 5$ & $11440 \cdot 6$ & $<0 \cdot 001$ \\
& sqrtarea & $170 \cdot 5$ & 1 & $170 \cdot 5$ & $61860 \cdot 3$ & $<0 \cdot 001$ \\
Length & width & $1 \cdot 222$ & 1 & $1 \cdot 222$ & $106 \cdot 3$ & $<0 \cdot 001$ \\
& sqrtarea & $1 \cdot 762$ & 1 & $1 \cdot 762$ & $636 \cdot 3$ & $<0 \cdot 001$ \\
Class & width & $0 \cdot 0053$ & 1 & $0 \cdot 0053$ & $0 \cdot 460$ & $0 \cdot 503$ \\
& sqrtarea & $0 \cdot 0034$ & 1 & $0 \cdot 0034$ & $1 \cdot 216$ & $0 \cdot 279$ \\
Error & width & $0 \cdot 356$ & 31 & $0 \cdot 0115$ & & \\
& sqrtarea & $0 \cdot 085$ & 31 & $0 \cdot 0028$ & & \\
Total & width & $133 \cdot 1$ & 34 & & & \\
Corrected Total & sqrtarea & $172 \cdot 3$ & 34 & & & \\
& width & $1 \cdot 584$ & 33 & & & \\
\hline \hline
\end{tabular}


Uninfected females vs Females infected with non-microphallid parasites

Tests of Between-Subjects Effects

\begin{tabular}{|c|c|c|c|c|c|c|}
\hline Source & $\begin{array}{l}\text { Dependent } \\
\text { Variable }\end{array}$ & $\begin{array}{l}\text { Type I Sum } \\
\text { of Squares }\end{array}$ & $\mathrm{df}$ & $\begin{array}{l}\text { Mean } \\
\text { Square }\end{array}$ & $\mathrm{F}$ & $P$ \\
\hline \multirow[t]{2}{*}{ Corrected Model } & width & $11 \cdot 02$ & 2 & $5 \cdot 509$ & $454 \cdot 1$ & $<0.001$ \\
\hline & sqrtarea & $21 \cdot 06$ & 2 & $10 \cdot 53$ & $1430 \cdot 2$ & $<0.001$ \\
\hline \multirow[t]{2}{*}{ Intercept } & width & $1078 \cdot 2$ & 1 & $1078 \cdot 2$ & $88871 \cdot 8$ & $<0 \cdot 001$ \\
\hline & sqrtarea & $1325 \cdot 0$ & 1 & $1325 \cdot 0$ & $179963 \cdot 9$ & $<0 \cdot 001$ \\
\hline \multirow[t]{2}{*}{ Length } & width & $11 \cdot 02$ & 1 & $11 \cdot 02$ & $908 \cdot 0$ & $<0 \cdot 001$ \\
\hline & sqrtarea & $21 \cdot 06$ & 1 & $21 \cdot 06$ & $2860 \cdot 0$ & $<0 \cdot 001$ \\
\hline \multirow[t]{2}{*}{ Class } & width & $0 \cdot 00099$ & 1 & $0 \cdot 00099$ & $0 \cdot 082$ & 0.775 \\
\hline & sqrtarea & $0 \cdot 00286$ & 1 & $0 \cdot 00286$ & $0 \cdot 389$ & 0.533 \\
\hline \multirow[t]{2}{*}{ Error } & width & $2 \cdot 851$ & 235 & $0 \cdot 0121$ & & \\
\hline & sqrtarea & $1 \cdot 730$ & 235 & $0 \cdot 0074$ & & \\
\hline \multirow[t]{2}{*}{ Total } & width & $1092 \cdot 12$ & 238 & & & \\
\hline & sqrtarea & $1347 \cdot 74$ & 238 & & & \\
\hline \multirow[t]{2}{*}{ Corrected Total } & width & $13 \cdot 87$ & 237 & & & \\
\hline & sqrtarea & $22 \cdot 79$ & 237 & & & \\
\hline
\end{tabular}

Microphallus-infected females vs Females infected with non-microphallid parasites

Tests of Between-Subjects Effects

\begin{tabular}{|c|c|c|c|c|c|c|}
\hline Source & $\begin{array}{l}\text { Dependent } \\
\text { Variable }\end{array}$ & $\begin{array}{l}\text { Type I Sum } \\
\text { of Squares }\end{array}$ & $\mathrm{df}$ & $\begin{array}{l}\text { Mean } \\
\text { Square }\end{array}$ & $\mathrm{F}$ & $P$ \\
\hline \multirow[t]{2}{*}{ Corrected Model } & width & $4 \cdot 667$ & 2 & $2 \cdot 333$ & $174 \cdot 158$ & $<0.001$ \\
\hline & sqrtarea & $8 \cdot 173$ & 2 & $4 \cdot 087$ & $578 \cdot 5$ & $<0.001$ \\
\hline \multirow[t]{2}{*}{ Intercept } & width & $567 \cdot 497$ & 1 & $567 \cdot 497$ & $42356 \cdot 6$ & $<0.001$ \\
\hline & sqrtarea & $726 \cdot 388$ & 1 & $726 \cdot 388$ & $102831 \cdot 1$ & $<0.001$ \\
\hline \multirow[t]{2}{*}{ Length } & width & $4 \cdot 653$ & 1 & $4 \cdot 653$ & $347 \cdot 32$ & $<0.001$ \\
\hline & sqrtarea & $8 \cdot 159$ & 1 & $8 \cdot 159$ & $1155 \cdot 1$ & $<0.001$ \\
\hline \multirow[t]{2}{*}{ Class } & width & $0 \cdot 01332$ & 1 & $0 \cdot 0133$ & $0 \cdot 994$ & $0 \cdot 321$ \\
\hline & sqrtarea & $0 \cdot 01403$ & 1 & $0 \cdot 0140$ & $1 \cdot 987$ & $0 \cdot 162$ \\
\hline \multirow[t]{2}{*}{ Error } & width & $1 \cdot 313$ & 98 & $0 \cdot 0134$ & & \\
\hline & sqrtarea & $0 \cdot 692$ & 98 & $0 \cdot 0070$ & & \\
\hline \multirow[t]{2}{*}{ Total } & width & $573 \cdot 476$ & 101 & & & \\
\hline & sqrtarea & $735 \cdot 253$ & 101 & & & \\
\hline \multirow[t]{2}{*}{ Corrected Total } & width & $5 \cdot 980$ & 100 & & & \\
\hline & sqrtarea & $8 \cdot 866$ & 100 & & & \\
\hline
\end{tabular}

